\title{
Mathematics Achievement Motivation in a Collectivist Culture: The Role of Gender Differences and Self-Efficacy
}

\author{
OLUTOLA AKINDIPE \\ College of Education, University of Georgia, 110 Carlton St, Athens, GA 30602 \\ USA. \\ E-mail: olutolaakindipe@yahoo.com
}

\begin{abstract}
We live in a computerized and technologically advanced age where mathematics-related disciplines represent the future. However, students from many collectivist cultures are underachieving in mathematics. Literature suggests that mathematics achievement and motivation are impacted by self-efficacy, yet the relationship between these variables in most collectivist cultures remains unclear. Also, empirical evidences of gender differences in mathematics self-efficacy and motivation studies exist, albeit, with generally inconsistent findings. This study examined the gender differences and the relationship between mathematics self-efficacy and motivation of students in a collectivist culture. Three hundred and forty three sixth grade students aged $9-13$ were randomly selected from 10 public and private elementary schools in Southwestern Nigeria. The participants consisted of 175 girls and 168 boys with mean age of 10.82. The mathematic self-efficacy and motivation measures were adapted from Pintrich et al's al.'s (1991) Motivated Strategies for Learning Questionnaire. Collected data was analyzed using independent t-test and Pearson's correlation analyses. Results revealed no significant gender differences in mathematics motivation and self-efficacy but showed that mathematics self-efficacy was positively correlated with motivation. Implications of the findings are discussed and recommendations suggested. Keywords: mathematics, self-efficacy, motivation, gender, collectivist culture
\end{abstract}

DOI: $10.7176 / \mathrm{JEP} / 10-3-11$

\section{Introduction}

The role of mathematics in the development of nations cannot be overemphasized; it is relevant not only in people's daily functioning but also in national growth and advancement. Mathematics underachievement remains a global educational issue affecting many countries, especially among collectivist cultures in the developing regions of the world (Marshall, DeCuir-Gunby, \& McCulloch, 2015). Due to the lack of adequate governmental funding that affects the availability of educational resources, training and remuneration of teachers, and research in mathematics, many students from developing countries do not perform well in mathematics, often failing at national and local mathematics examinations (Aburime, 2007). However, it is in mathematics-related disciplines that several scientific and technological knowledge and skills that are needed to solve societal problems such as food insecurity, health epidemics and environmental degradation and to effectively develop societies can be acquired.

In addition, gender inequality in educational opportunities seems to be a prevalent issue in collectivist cultures. Through the process of socialization, girls are steered towards social roles such as doing house chores and taking care of younger siblings while those who live in the villages and rural areas are often given away in marriage at an early age. Girls who are in school are often discouraged from pursuing careers in mathematics and other male dominated disciplines. Differences in male and female mathematics performances have been widely reported in studies conducted in collectivist cultures; albeit with inconsistent findings. Although many studies have concluded that male students perform better in mathematics compared to their female counterparts (Adeneye \& Adeleye, 2011; Bassey, Joshua, \& Asim, 2007) others have reported that female students performed better in the subject than male students (Robinson \& Lubienski, 2011; Muthukrishna \& Kwela, 2010; Fabiyi, 2017). Some studies, however, found no gender difference in students' mathematics achievement (Adebule \& Imoko, 2014; Ajai \& Imoko, 2015). Despite these conflicting findings, the fact remains that females are underrepresented in the Science, Technology, Engineering and Mathematics (STEM) disciplines. They have lower enrollment and graduation rates in college and less presence in the male-dominated careers (Watt, 2006). Moreover, female participation in these careers is low, and they are rarely found in top managerial and leadership positions (United Nations Educational, Scientific and Cultural Organization, UNESCO, 2016).

One factor that has been consistently linked to students' mathematics underachievement is motivation (Fan \& Williams, 2010; Gonzalez \& Wolters, 2006). Motivation is the force that propels people to do things. Basically, it can either be intrinsic or extrinsic (Ryan \& Deci, 2000). Intrinsic motivation deals with the internal pleasure, fulfillment or satisfaction that an individual obtains from performing a task (Deci \& Ryan, 1991), while extrinsic motivation refers to the external factors that influence an individual to perform a task (Ryan \& Deci, 2000). Motivation exerts a powerful influence on people's behavior during learning. Specifically, it engenders attention, effort, engagement, persistence, participation and personal fulfillment (Pintrich \& Schunk, 2002). 
Mathematics motivation is crucial to mathematics achievement. It is a significant predictor of students' mathematics achievement (Mega, Ronconi, \& De Beni, 2014).

Also instrumental in influencing mathematics motivation is self-efficacy (Schunk, 1991; Pajares, 1996). Self-efficacy is defined as the personal judgment of one's capabilities to organize and execute courses of action to attain specific goals or objectives (Bandura, 1997). It represents a cognitive approach to the understanding of people's expectations and motivation (Bandura, 1986), and develops within a socio-cultural network of influences (Adeyemo, 2005). Self-efficacy energizes students to exert effort and persevere when performing challenging tasks (Huang, 2013). Furthermore, it influences students affectively and cognitively before and during learning (Bandura, 2012; Britner \& Pajares, 2006). Self-efficacy has been found to be the most significant predictor of students' achievement (Schunk \& Miller, 2002; Britner \& Pajares, 2006), transcending both cognitive ability and prior achievement (Pajares, 1996; Pajares \& Miller, 1994). Students with higher selfefficacy work harder, invent more strategies, persist at tasks, and have better performance compared to those with lower self-efficacy (Chang, 2010; Pintrich \& DeGroot, 1990).

The relationship between mathematics self-efficacy and achievement motivation has been outlined in several studies. Soleymani and Rekabdar (2016) reported a positive relationship between mathematics selfefficacy and mathematics achievement. Similarly, Pintrich and DeGroot (1990), Zhang et al. (2015), and Caprara, Vecchione, Alessandri, Gerbino, and Barbaranelli (2011) reported a significant positive correlation between mathematics self-efficacy and mathematics achievement motivation.

\section{1. Collectivist Cultures}

One of the most widely known classifications of cultures is Triandis' (1995) individualism-collectivism. Collectivist cultures are those that value the group's norms, interests, goals, and utilities. Members derive their sense of identity and self-worth from their connectedness with other members of the group thus leading to a high level of interdependence (Hui \& Triandis, 1986; Hofstede, 1997). They believe in the collective self and behaving in a communal way (Gorodnichenko \& Roland, 2012; Bong, Hwang, Noh, \& Kim, 2014). In contrast, individualistic cultures are characterized by independence, self-sufficiency, autonomy, competition, and the development of a personal self, goals, and values (Bong et al., 2014). There is a high premium on freedom, competition, and personal accomplishment among members of individualistic cultures.

Historically, most non-Western countries are considered collectivist cultures. Although the level of collectivism may vary from country to country (Rhee, Uleman, \& Lee, 1996), most Asian, South American and African countries are generally classified as collectivist cultures (Hofstede, 1980; Triandis, 1989). However, for the purpose of this study I used Nigeria, a developing country whose culture is also collectivist.

Usually, gender differences in mathematics may be more prevalent in a collectivist culture (Parker \& Pederzini, 1999) because they are patriarchal in nature and hold traditional beliefs that the man is the head of the family while women are to care for and support the family. This notion leads to gender inequality that often favors males over females (Parker \& Pederzini, 1999; Dormekpor, 2015). Also, most collectivist cultures, through the process of socialization, maintain cultural roles, values, and expectations that cause girls to believe that mathematics is a masculine subject that they are incapable of exceling in (Meece \& Scantlebury, 2006). Consequently, this reduces their interest in the subject and limits them in pursuing careers in mathematics-related disciplines (Eccles, 2007; Meece \& Courtney, 1992).

\subsection{Self-efficacy and Culture}

Self-efficacy beliefs originate and develop within a cultural context. Bandura (1986) postulated four different sources of self-efficacy development. These are mastery, vicarious experiences, verbal persuasion, and physiological arousal. Mastery emanates from the personal experiences that are acquired during the performance of a task. It represents the most influential source of efficacy because it provides authentic evidence that an individual is competent and can be successful at a task (Bandura, 1997). Vicarious experience comes from observing others perform a task. Verbal persuasion is the feedback received during the performance of a task while physiological arousal involves bodily sensations such as calmness and anxiety, which are experienced during the performance of a task.

Information from each self-efficacy source is unique and experienced differently, leading to variations in the development of self-efficacy (Bandura, 1997; Scholz et al., 2002). Specifically, cultural differences in the attainment, selection, weight, integration and communication of information as well as the importance and degree of exposure attached to the self-efficacy sources determine their strength and influence. Likewise, the successful implementation of information obtained from these sources during social interactions or task performances impacts self-efficacy (Oettingen, 1995).

Although several studies have highlighted the significance and universality of self-efficacy as a construct transcending cultures (Bandura, 1997; Stevens, Olivárez, Lan, \& Tallent-Runnels, 2004), few studies have reported differences in the self-efficacy beliefs of students from different cultures. For instance, Bong et al. 
(2014) and Ahn, Usher, Butz, and Bong (2016) suggested that students from collectivist cultures possess lower self-efficacy beliefs in comparison to those from individualistic cultures. In contrast, Shneor, Camgöz and Karapinar (2013) found that collectivist students had higher self-efficacy than individualistic students.

\subsection{Gender Differences in Mathematics Self-efficacy and Motivation}

Research findings on gender differences in mathematics self-efficacy and motivation studies are mixed. While some studies report girls having higher mathematics self-efficacy than boys (Recber, Isiksal, \& Koc, 2018; Louis \& Mistele, 2012), others have indicated that boys' mathematics self-efficacy is higher than that of girls (Pintrich \& Degroot, 1990; Zhang et al., 2015). Also, some studies reported that boys have higher mathematics motivation than girls (Wentzel, Battle, Russell, \& Looney, 2010; Frenzel, Goetz, Pekrun, \& Watt, 2010; Else-Quest, Hyde, \& Linn, 2010), while other studies concluded that girls' mathematics motivation was higher than that of boys (Jaen \& Baccay, 2016).

However, some studies found no gender difference in students' mathematics self-efficacy and achievement motivation, thereby suggesting that the mathematics gender gap is decreasing (Pajares \& Kranzler, 1995; Ayotola \& Adedeji, 2009). Furthermore, these studies have indicated that female students are performing almost as well as their male counterparts in mathematics (Hyde \& Mertzb, 2009), are developing greater mathematics skills and taking more STEM courses than they did in the last few decades (Perie, Moran, \& Lutkus, 2005). Some of these findings might be attributed to changes in gender patterns in the twenty-first century where there has been an increase in the global awareness of and campaign for gender equality, especially in mathematics education, and more opportunities for girls to learn and succeed in mathematics. In the United States, programs such as Girls Who Code and Girls Exploring Math and Science (GEMS) have engendered more interest and participation in mathematics. Similarly, some government policies and programs in collectivist cultures of developing nations have been established to motivate girls to learn and excel in mathematics. For instance, the National Policy on Women, the Blueprint on Women's Education, and the Strategy for Acceleration of Girl Education are some of the several programs implemented by the Nigerian government to provide girls with incentives to study mathematics-related subjects (British Council, 2012).

Although there has been an increase in the mathematics motivation literature, the focus is still mostly on Western cultures. There is a dearth of mathematics motivational studies from non-Western or collectivist cultures especially in developing countries. Consequently, there is little understanding of the mathematics selfefficacy and motivation, especially with respect to gender, of students from these cultures. The purpose of this study, therefore, was to investigate the relationship between the mathematics self-efficacy and achievement motivation of students in a collectivist culture. Also, the study sought to determine if there are gender differences in students' mathematics self-efficacy and motivation. The results of this study could enhance parents', educators', and mathematics teachers' understanding of the mathematics self-efficacy and motivation of students from collectivist cultures in order to increase students' performances and participation in mathematics related careers. In addition, the findings could provide in-depth comprehension of the mathematics motivation of students from diverse backgrounds with the aim of enhancing it. To this end, the following research hypotheses were generated for the study: (a) there will be a significant difference between the mathematics self-efficacy of male and female students; (b) there will be a significant difference between the mathematics achievement motivation of male and female students; and (c) there will be a significant positive relationship between the mathematics self-efficacy and achievement motivation of students.

\section{Expectancy-Value Theory}

Comprising the interplay of two factors, expectancy for success and task value, the expectancy-value theory (Eccles, Wigfield, \& Schiefele, 1998) represents one of the earliest theories explaining human motivation. Expectancy for success is the anticipation that a task performance will meet with success or failure, while task value is the relative attractiveness of succeeding or failing at a task (Wigfield \& Eccles, 2000). Expectancy for success is determined by the perception of task difficulty and self-schema. Task difficulty is the perceived level of ease or difficulty in performing a task, while self-schema is one's perception of self, based on past and current experiences. Task value consists of four components: attainment value, intrinsic value, utility value, and cost (Eccles et al., 1983). Attainment value refers to the personal importance of accomplishing a task (Eccles, 2009). Intrinsic value refers to the pleasure or enjoyment derived from performing a task, utility value speaks of the extent to which a task fits into a plan and the realization of important current and future goals, and cost refers to whatever an individual gives up or forgoes in order to perform a task.

Crucial to motivation within the expectancy-value framework are some socio-cognitive factors such as beliefs, values, attitudes, and expectations of the individual (Eccles et al., 1983; Valverde \& Castenell, 1998). These factors are acquired with the sociocultural environment thereby making the individual's culture the bedrock for the incubation and development of his or her beliefs, values, attitudes, behaviors and ultimately motivation. Similarly, culture also plays an important role in the cognitive interpretation given to these factors, 
which invariably makes motivation a subjective construct. Motivation, therefore, is at its highest when an individual cognitively perceives and interprets his or her value and expectation for success as being on the highest levels. Students who perceive themselves as capable of succeeding at a task and who find the task valuable will have higher motivation than those who view the task as worthless, meaningless, and who also believe that they are incapable of successfully performing it.

\section{Method}

\subsection{Participants}

The participants used in this study were 343 sixth grade students that were randomly selected from 10 public and private schools in Lagos, a metropolitan city in Southwestern Nigeria, a collectivist culture. Consisting of 175 (50.6\%) girls and $168(48.7 \%)$ boys, the mean age of the participants was 10.82 . The mean ages for the female and male participants were 10.81 and 10.83, respectively. The youngest participant was 9 years old while the oldest was 13 years. The subjects were very diverse, with most of the ethnic groups in the country represented.

\subsection{Procedure}

After securing approval from the University of Georgia Institutional Review Board and the Lagos State Universal Basic Education Board (LSUBEB), the governmental agency in charge of elementary schools in Lagos State, Nigeria, the researcher contacted the head teachers of the selected schools and obtained their permission to use their schools and students in the study. The researcher met with grade six students in each school and briefed them about the study. Using a list generated by the head teachers, forty students were randomly selected from the sixth grade in each school using a paper ballot system. Informed consent was obtained from the participants and parental permissions were sent to their parents or guardians. Fifty-three students failed to obtain parental consent and were excluded from participation in the study. Questionnaires were administered to the participants about a week later during a free class period. Two questionnaires were improperly filled and could not be included in the statistical analysis.

\subsection{Instrument}

A student self-report questionnaire elicited information on participant's socio-demographic variables such as age, gender, socioeconomic status, and parents' educational qualification among others, and also contained the mathematics self-efficacy and mathematics motivation measures.

The mathematics self-efficacy and motivation measures were adapted from Pintrich et al.'s (1991) Motivated Strategies for Learning Questionnaire (MSLQ) subscales. The MSLQ has high validity and reliability and has been extensively used in several self-regulated learning and motivation studies (Artino, 2005). The items were formatted after a 4-point Likert scale as opposed to the 7-point scale of the original measure. This was to make the response options optimal and easy for the students to fill. The responses ranged from 'Not true at all' (1) to 'Very true' (4). The mathematics self-efficacy measure consisted of 11 items and some items were slightly reworded for easier comprehension and applicability to the study. For example, an item that read "I expect to do very well in this class" was rephrased to "I expect to do very well in my mathematics class." The internal consistency reliability coefficient, Cronbach Alpha, of the mathematics self-efficacy measure was .93. The mathematics achievement motivation measure had 12 items comprising nine and three items on intrinsic and extrinsic motivation, respectively. The Cronbach Alphas of the MSLQ intrinsic and extrinsic items were .74 and .62, respectively (Artino, 2005).

\section{Results}

To determine if the self-efficacy of female students was significantly different from that of male students, an independent t-test was conducted to compare the means of the two groups. Levene's test for the assumption of homogeneity of variances $(\mathrm{F}(339)=.113, p=.737)$ and the normality test were satisfied (skew $=-1.7$; kurtosis $=3.1)$. Although the male students $(M=3.41, S D=0.42)$ had higher self-efficacy than the female respondents $(M=3.36, S D=0.46)$, this difference was not found to be statistically significant $t(339)=1.06, p=.292 ; d=$ $0.12 ; 95 \%$ CI $(-.04, .14)$. The effect size was within the range of Cohen's (1988) convention of a small effect. This result suggests that there was no gender difference in the students' mathematics self-efficacy.

An independent t-test analysis was carried out to determine if the mathematics achievement motivation of the female students was significantly different from that of the male students. Levene's test for the assumption of equal variance was violated by the analysis $(\mathrm{F}(339)=4.87, p=.028)$; therefore, a t-test of equal variances not assumed was utilized. Female students had higher mathematics achievement motivation $(M=3.71, S D=0.34)$ in comparison to the male students $(M=3.67, S D=0.42)$; however, the difference was not found to be statistically significant $t(322.35)=-1.01, p=.311 ; d=0.11 ; 95 \%$ CI $(-.12, .04)$. Cohen's effect size was found to be small, suggesting a small effect. This result, therefore, indicates that the mathematics achievement motivation of male students was not different from that of female students. 
Pearson's correlation analysis was employed to find out the relationship between students' mathematics self-efficacy and achievement motivation. A significant positive correlation was found between mathematics self-efficacy and mathematics achievement motivation $(r(339)=.58, p<.001)$. This means that there was a moderate positive relationship between mathematics self-efficacy and mathematics achievement motivation, meaning that as students' mathematics self-efficacy increases, their mathematics achievement motivation will also increase. The effect size, partial eta square, was found to be medium $\left(\mathrm{r}^{2}=.34\right)$, demonstrating that students' mathematics self-efficacy accounted for about $34 \%$ of the total variance in mathematics achievement motivation.

\section{Discussion}

Many collectivist cultures especially in the developing parts of the world have sociocultural practices that ingrain gender inequality not only in education but in mathematics learning. Such practices have limited and hindered females' opportunities and contribution towards national development. The hypothesis stating that there will be a significant difference between the mathematics self-efficacy of male and female students was not supported by the results of the study. This finding is consistent with the study conducted by Ayotola and Adedeji (2009) which found no significant statistical difference in the mathematics self-efficacy of male and female students. However, the result contradicts the findings of Louis and Mistele (2012), Recber et al. (2018), and Eccles et al. (1993) which concluded that female students displayed higher self-efficacy than male students and Zhang et al. (2015) which found that male students had higher self-efficacy than their female counterparts.

Similarly, the result of the study shows no statistically significant gender difference in students' mathematics motivation, thus failing to support the hypothesis that male and female students will have different mathematics motivation. This finding is in contrast with studies conducted by Dever and Karabenick (2011), Skaalvik and Skaalvik (2004), and Preckel et al., (2008) which revealed that boys were more motivated than girls in mathematics; in addition it is contrary to the findings of Stomberg and Nilsson (2010) which reported that females were more motivated than males.

The evidence of no gender difference in the students' mathematics self-efficacy and motivation suggests that collectivist cultures, which are traditionally more favorable towards males than females, seem to be changing. These findings indicate that girls in collectivist cultures might just be as motivated and confidence of learning and excelling in mathematics as much as boys. Therefore, more efforts should be directed to increase male and female students' mathematics motivation, however, greater encouragement and opportunities should be given to girls. This may not only bring them to a mathematical level that is commensurate with their interest or motivation but may also significantly increase their participation in the STEM fields.

A plausible reason for this result might be recent educational changes which have allowed more female students to learn mathematics. Educational initiatives by the Nigerian government such as the National Policy on Women, Family Support Basic Education, and the Blueprint on Women's Education have encouraged more girls to stay in school and learn mathematics. These programs might have boosted their confidence and motivation in the subject. However, to sustain their mathematics self-efficacy and motivation, governments must not only continue but improve and implement more of these programs. Only then can there be higher mathematics achievement and a full representation of both males and females in STEM careers.

Also, the result of this study supports the hypothesis that there is a positive relationship between students' mathematics self-efficacy and achievement motivation. This result is consistent with the study carried out by Zhang et al. (2015) and Caprara et al. (2011) which found a positive relationship between mathematics selfefficacy and achievement motivation. In other words, students who had higher mathematic self-efficacy also had higher mathematics motivation than those with lower self-efficacy, thus corroborating the findings of Bandura (1986) which asserted that self-efficacy is important to mathematics motivation.

\section{Conclusion and Recommendations}

A strong correlation between students' mathematics self-efficacy and achievement motivation supports the universality of self-efficacy as asserted by Bandura (1997). In other words, higher self-efficacy is vital to students' mathematics motivation and achievement. Policy makers, parents, teachers, and school administrators must work independently as well as collaboratively to boost students' mathematics self-efficacy beliefs. One way of achieving this to train teachers to develop students' mathematics mastery through establishing simple precept-upon-precept learning approaches. Furthermore, teachers should actively engender students' interest in mathematics by making learning applicable to their experiences. Parents should enhance their children's mathematics self-efficacy and motivation by emphasizing the value and usefulness of mathematics to daily functioning such as in paying for groceries and sharing things among friends. Also, government and corporate organizations should contribute to the development of mathematics by donating for the purchase of learning resources, the training of mathematics teachers, sponsorship of mathematics competitions and scholarships for students of exceptional mathematical abilities.

There are several limitations to this study. First, because the research was a correlational study, it is 
impossible to infer causality. Second, the study utilized the students' self-report for all data collected. Future studies might consider using other forms of assessments such as parents' or teachers' reports, observations, and structured interviews. The use of multiple measures might eliminate the possible bias that could be associated with single-source data. Third, the study was conducted in an urbanized region of the state. Although all Nigerians are generally considered to be collectivist, the inclusion of students from rural communities in future studies might provide a more comprehensive perspective to studying the collectivist culture. Also, the finding of this study might be generalizable to all collectivist cultures in the developing world. While the scope of the study was limited to gender differences in mathematics self-efficacy and motivation, further work might be needed to examine the effects of socio-economic status such as mothers' and father's educational qualification on mathematics motivation. In addition, future research might consider examining gender as a moderator of the relationship between mathematics self-efficacy and motivation in order to see if it helps to explain the relationship.

In sum, this study provides some insights to the mathematics motivational outcomes of students from a collectivist culture such as the importance of mathematics self-efficacy to students' mathematics motivation, and that girls might be as capable of learning mathematics as boys, if they are provided with the right environment and learning opportunities.

\section{References}

Aburime, F. E. (2007). How manipulative affect the mathematics achievement of students in Nigerian schools. Educational Research Quarterly, 31(1), 3-16.

Adebule, S O, \& Aborisade, O. J. (2014). Gender comparison of attitude of senior secondary school students towards mathematics in Ekiti State, Nigeria. European Scientific Journal, 10(19), 153-160.

Adeneye, O. \& Adeleye, A. (2011). Is Gender a Factor in Mathematics Performance among Nigerian Senior Secondary Students with Varying School Organization and Location? International Journal of Mathematics Trends and Technology, 2(3), 17-21.

Adeyemo, D. A. (2005). Parental involvement, interest in schooling and school environment as predictors of academic self-efficacy among fresh secondary school students in Oyo State, Nigeria. Electronic Journal of Psychology of Education, 5(3), 1-15.

Ajai, J. T. \& Imoko, I. I. (2015). Gender differences in mathematics achievement and retention scores: A case of problem-based learning method. International Journal of Research in Education and Science (IJRES), 1(1), 45- 50.

Ahn, H. S., Usher, E. L., Butz, A., \& Bong, M. (2016). Cultural differences in the understanding of modeling and feedback as sources of self - efficacy information. British Journal of Educational Psychology, 86(1), 112136.

Artino, A. R. (2005). Review of the motivated strategies for learning questionnaire. Retrieved from https://eric.ed.gov/?id=ED499083

Ayotola, A., \& Adedeji, T. (2009).The relationship between mathematics self-efficacy and achievement in mathematics. Procedia Social and Behavioral Sciences, 953-957. https://doi.org/10.1016/j.sbspro.2009.01.169

Bandura, A. (1986). Social foundations of thought and action: A social cognitive theory. Englewood Cliffs, NJ: Prentice Hall.

Bandura, A. (1997). Self-efficacy: The exercise of control. New York, NY: Freeman.

Bandura, A. (2012). Social Cognitive Theory. In P A. M. Van Lange, A W. Kruglanski \& E. T. Higgins (Eds.), Handbook of theories of social psychology (Vol. 1, pp. 349-375) Washington, DC: Sage.

Bassey, S. W., Joshua, M. T., \& Asim, A. E. (2007). Gender differences and mathematics achievement of rural senior secondary students in Cross River State, Nigeria. Retrieved from http://web.gnowledge.org/episteme3/pro_pdfs/09-bassvjoshua-asim.pdf.

Bong, M., Hwang, A., Noh, A., \& Kim, S. (2014). Perfectionism and motivation of adolescents in academic contexts. Journal of Educational Psychology, 106, 711- 729.

Britner, S. L., \& Pajares, F. (2006). Sources of science self-efficacy beliefs of middle school students. Journal of Research in Science Teaching, 43, 485-499. 2012

British Council (2012). Gender in Nigeria report 2012: Improving the lives of girls and women in Nigeria. Issues, policies, actions. 2nd Edition.

Caprara, G. V., Vecchione, M., Alessandri, G., Gerbino, M., \& Barbaranelli, C. (2011). The contribution of personality traits and self-efficacy beliefs to academic achievement: A longitudinal study. British Journal of Educational Psychology, 81, 78-96.

Chang, Y. L. (2010). A case study of elementary beginning mathematics teachers' efficacy development. International Journal of Science and Mathematics Education, 8(2), 271-297.

Deci, E. L., \& Ryan, R. M. (1991). A motivational approach to self: Integration in personality. In R. Dienstbier 
(Ed.), Nebraska symposium on motivation: Vol. 38, Perspectives on motivation (pp. 237-288). Lincoln: University of Nebraska Press.

Dormekpor, E. (2015). Poverty and gender inequality in developing countries. Developing Country Studies, 5(10). Retrieved from http://www.iiste.org/Journals/index.php/DCS/article/viewFile/22475/22688

Eccles, J. S. (2007). Where are all the women? Gender differences in participation in physical science and engineering. In S. J. Ceci, \& W. M. Williams (Eds.), Why aren't more women in science? Top researchers debate the evidence (pp. 199-210). Washington DC: American Psychological Association.

Eccles, J. S. (2009). Who am i and what am i going to do with my life? Personal and collective identities as motivators of action. Educational Psychologist, 44, 78-89. doi: 10.1080/00461520902832368

Eccles J. S., Adler, T. F., Futterman, R., Goff, S. B., Kaczala, C. M., Meece, J. L., \& Midgley, C. (1983). Expectancies, values, and academic behaviors. In J. T. Spence (Ed.), Achievement and achievement motivation, 75-146. San Francisco, CA: W. H. Freeman.

Eccles, J. S., Wigfield, A., Harold, R. D., \& Blumenfeld, P. (1993). Age and gender differences in children's self- and task perceptions during elementary school. Child Development, 64, 830-847.

Eccles, J. S., Wigfield, A., \& Schiefele, U. (1998). Motivation to succeed. In W. Damon (Series Ed.) and N. Eisenberg (Vol. Ed.), Handbook of child psychology (5th Ed.), 3, 1017-1095. New York: Wiley.

Else-Quest, N. M., Hyde, J. S., \& Linn, M. C. (2010). Cross-national patterns of gender differences in mathematics: A meta-analysis. Psychological Bulletin, 136, 103-127.

Fabiyi, T. R. (2017). Geometry concepts in mathematics perceived difficult to learn by senior secondary school students in Ekiti State, Nigeria. Journal of Research \& Method in Education (IOSR-JRME), 7(1), 83-90. doi: $10.9790 / 7388-0701018390$

Fan, W., \& Williams, C. (2010). The effects of parental involvement on students' academic self-efficacy, engagement and intrinsic motivation. Educational Psychology, 30(1), 53-74. doi: 10.1080/01443410903353302.

Frenzel, A. C., Goetz, T., Pekrun, R., \& Watt, H. M. G. (2010). Development of mathematics interest in adolescence: Influences of gender, family, and school context. Journal of Research on Adolescence, 20(2), 507-537

Gonzalez, A., \& Wolters, C. (2006). The relation between perceived parenting practices and achievement motivation in mathematics. Journal of Research in Childhood Education, 21, 203-217.

Gorodnichenko, Y., \& G. Roland (2012). "Understanding the individualism-collectivism cleavage and its effects: Lessons from cultural psychology." In M. Aoki, T. Kuran, \& G. Roland (Eds.), Institutions and Comparative Economic Development (pp. 213-236) London: Palgrave McMillan.

Hofstede, G. (1980). Culture's consequences. Beverly Hills, CA: Sage.

Hofstede, G. (1997). Cultures and organizations: Software of the mind. New York: McGraw-Hill.

Huang, C. (2013). Gender differences in academic self-efficacy: a meta-analysis. European Journal of Psychological Education, 28, 1-35. Retrieved from https://doi.org/10.1007/s10212-011-0097-y

Hui, C. H., \& Triandis, H. C. (1986). Individualism collectivism: A study of cross-cultural researchers. Journal of Cross-Cultural Psychology, 17, 225-248. doi:10.1177/0022002186017002006

Hyde, J. S., \& Mertz, J. E. (2009). Gender, culture, and mathematics performance. Proceeding of the National Academy of Sciences, 106(22), 8801-8807. doi:10.1073/pnas.0901265106

Jaen, M. C. A., \& Baccay, E. S. (2016). Curiosity, motivation, attitude, gender, and mathematics performance. The Normal Lights: Journal on Teacher Education, 10(2), 89-103. Retrieved from http://po.pnuresearchportal.org/ejournal/index.php/normallights/article/view/255

Louis, R. A., \& Mistele, J. M. (2012). The differences in scores and self-efficacy by student gender in mathematics and science. International Journal of Science and Mathematics Education, 10(5), 1163-1190. Doi: 10.1007/s10763-011-9325-9

Meece, J. L., \& Courtney, D. P. (1992). Gender differences in students' perceptions: Consequences for achievement-related choices. In D.H. Schunk, \& J.L. Meece (Eds.), Student perceptions in the class-room (pp. 209-228). Hillsdale, NJ: Erlbaum.

Marshall, P. L., DeCuir-Gunby, J. T. \& McCulloch, A. W. (2015). When critical multiculturalism meets mathematics: A mixed methods study of professional development and teacher identity. Maryland: Rowman and Littlefield,

Meece, J. L., \& Scantlebury, K. (2006). Gender and schooling: progress and persistent barriers, In J. Worrell \& C. Goodheart (Eds.), Handbook of Girls' and Women's Psychological Health (pp. 283-91), NY: Oxford University Press.

Mega, C., Ronconi, L. \& De Beni, R. (2014). What makes a good student? How emotions, self-regulated learning, and motivation contribute to academic achievement. Journal of Educational Psychology, 106(1), 121-131. doi: 10.1037/a0033546

Muthukrishna, N. \& Kwela, C.B. (2010). Gender differences in mathematics achievement: An exploratory study 
at a primary school in Kwazulu-Natal. Gender and Behavior, 8(2), 3290-3313. Retrieved from http://dx.doi.org.proxy-remote.galib.uga.edu/10.4314/gab.v8i2.61948

Nilsson, K.E. \& Stomberg, M.I. W. (2008). Nursing students' motivation toward their studies - a survey study. BMC Nursing, 7, 6-10. doi: 10.1186/1472-6955-7-6

Oettingen, G. (1995). Explanatory style in the context of culture. In G. M. Buchanan \& M. E. P. Seligman (Eds.), Explanatory style (pp. 209-224). Hillsdale, NJ: Erlbaum.

Pajares, F. (1996). Self-efficacy beliefs and mathematical problem solving of gifted students. Contemporary Educational Psychology, 21(4), 325-344.

Pajares, F., \& Kranzler, J. (1995). Self-efficacy beliefs and general mental ability in mathematical problemsolving. Contemporary Educational Psychology, 20, 426-443.

Pajares, F., \& Miller, M.D. (1994). Role of self-efficacy and self- concept beliefs in mathematical problem solving: A path analysis. Journal of Educational Psychology, 86, 193-203.

Parker, S. W., \& Pederzini, C (2000). "Gender differences in education in Mexico." World Bank Departmental Working Paper 21023. Washington, D.C. Retrieved from

http://documents.worldbank.org/curated/en/659741468752986916/pdf/multi-page.pdf

Perie, M. L., Moran, R., \& Lutkus, A. D. (2005). NAEP 2004 Trends in Academic Progress: Three Decades of Student Performance in Reading and Mathematics (NCES 2005-464). U.S. Department of Education, Institute of Education Sciences, National Center for Education Statistics. Washington DC: Government Printing Office. Retrieved from https://nces.ed.gov/nationsreportcard/pdf/main2005/2005464.pdf

Pintrich, P.R., \& DeGroot, E.V. (1990). Motivational and self-regulated learning components of classroom academic performance. Journal of Educational Psychology, 82, 33-40.

Pintrich, P. R., \& Schunk, D. H. (2002). Motivation in education: Theory, research, and applications (2nd Ed.). Upper Saddle River, NJ: Prentice Hall.

Pintrich, P. R., Smith, D., Garcia, T., \& McKeachie, W. (1991). A manual for the use of the motivated strategies for learning questionnaire (MSLQ). The University of Michigan, Ann Arbor, MI. Retrieved from https://files.eric.ed.gov/fulltext/ED338122.pdf

Preckel, F., Goetz, T., Pekrun, R., \& Kleine, M. (2008). Gender differences in gifted and average-ability students: Comparing girls' and boys' achievement, self-concept, interest, and motivation in mathematics. Gifted Child Quarterly, 52(2), 146-159. Retrieved from http://dx.doi.org.proxyremote.galib.uga.edu/10.1177/0016986208315834

Recber, S., Isiksal, M. \& Koç, Y. (2018). Investigating self-efficacy, anxiety, attitudes and mathematics achievement regarding gender and school type. Anales de Psicología, 34(1), 41-51.

Rhee, E., Uleman, J. S., \& Lee, H. K. (1996). Variations in collectivism and individualism by in-group and culture: Confirmatory factor analyses. Journal of Personality and Social Psychology, 71(5), 1037-1054.

Robinson, J. P., \& Lubienski, S. T. (2011). The development of gender achievement in mathematics and reading during elementary and middle school: Examining direct cognitive assessments and teacher ratings. American Educational Research Journal, 48(2), 268-302.

Ryan, R. M., \& Deci, E. L. (2000). Intrinsic and extrinsic motivations: Classic definitions and new directions. Contemporary Educational Psychology, 25, 54-67.

Scholz, U., Dona, B., Sud, S., \& Schwarzer R. (2002) Is general self-efficacy a universal construct? European Journal of Psychological Assessment, 18, 242-251. doi: 10.1027//1015-5759.18.3.242

Schunk, D.H. (1991). Self-efficacy and academic motivation. Educational Psychologists. 26, 207-231.

Schunk, D. H., \& Miller, S. D. (2002). Self-efficacy and adolescents' motivation. In F. Pajares \& T. Urdan (Eds.), Academic motivation of adolescents (pp. 29-52). Greenwich, CT: Information Age.

Shneor, R., Camgöz, S. M., \& Karapinar, P. B. (2013). 'The interaction between culture and sex in the formation of entrepreneurial Intentions.' Entrepreneurship and Regional Development, 25(9-10), 781-803. http://dx.doi.org/10.1080/08985626.2013.862973

Skaalvik, S., Skaalvik, E.M. (2004).Gender differences in Math and verbal self-concept, performance expectations and motivation. Sex Role: 50 (3-4), 241-252.

Soleymani, B., \& Rekabdar, G. (2016). Relation between math self-efficacy and mathematics achievement with control of math attitude. Applied Mathematics, 6(1), pp. 16-19. doi:10.5923/j.am.20160601.03

Stevens T., Olivárez, A., Lan W. Y., \& Tallent-Runnels, M. K. (2004). Role of mathematics self-efficacy and motivation in mathematics performance across ethnicity. Journal of Educational Research, 97, 208-221.

Triandis, H. C. (1989). The Self and Social Behavior in differing Cultural Contexts. Psychological Review, 96, 269-89.

Triandis, H. C. (1995). Motivation and achievement in collectivist and individualist cultures. Advances in Motivation and Achievement, 9, 1-30.

UNESCO (2016). Closing the gender gap in STEM: Drawing more girls and women into Science, Technology, Engineering and Mathematics. Asia-Pacific Education Thematic Brief, 1-4. 
Valverde, L. A., \& Castenell, L. A. (1998). Multicultural campus: Strategies for transforming higher education. Walnut Creek, CA: Alta Mira.

Watt, H. M. G. (2006). The role of motivation in gendered educational and occupational trajectories related to maths. Educational Research and Evaluation, 12(4), 305-322.

Wentzel, K. R., Battle, A., Russell, S. L., \& Looney, L. B. (2010). Social supports from teachers and peers as predictors of academic and social motivation. Contemporary Educational Psychology, 35, 193-202. https://doi.org/10.1016/j.cedpsych.2010.03.002

Wigfield, A. \& Eccles, J. S. (2000). Expectancy-value theory of achievement motivation. Contemporary Educational Psychology, 25, 68-81. doi:10.1006/ceps.1999.1015

Zhang, Z., Zhang, C., Zhang, X, Liu, X., Zhang, H., Wang, J.\& Liu, S. (2015). Relationship between selfefficacy beliefs and achievement motivation in student nurses. Chinese Nursing Research, 2(2), 67-70. https://doi.org/10.1016/j.cnre.2015.06.001 